\title{
Pekerja Rumah Tangga (PRT) dan penerimaan terhadap makna spiritual dalam tayangan religi di televisi
}

\author{
Domestic workers and their interpretation of religion soap opera's spiritual \\ meaning
}

\author{
Reny Triwardani dan Panji Dwi Asrianto \\ Prodi Ilmu Komunikasi, Universitas Pembangunan Nasional "Veteran", Yogyakarta \\ Jalan Babarsari no 2 Tambakbayan, Yogyakarta, Indonesia \\ E-mail: reny.triwardani@gmail.com
}

\begin{abstract}
Religious soap opera is a tv shows that display story and culture which related to Islam within its story line. Different representations within religoius soap opera could lead to various interpretations. The text displayed posses dynamic values, particularly about how a text receive a value after being consumed by its audience. This research aims to describe audience acceptance level of spiritual meaning in religion tv shows. TV programs that had been observed were Layar kemilau (MNC TV) and sinema Pintu Taubat (Indosiar). This research uses descriptive qualitative method with in depth interview using 3 informants. Stuart Hall acceptance analysis was was used to identify two from three different affeptance models; dominant and negotiating. This research identify dominant and negotiating audience as informant to answer the research question. Informant background, peer group influence, the need of enterainment and audience gender were founded as significant inlfluencer of domestic workers'decision to watch religion soap opera in TV. This research shows that different interpretation obtained the audience can be reciprocal or contradict with the content of religious soap opera in TV.
\end{abstract}

Keywords: religious soap operas, reception analysis, dominant spectator, spectators negotiate, domestic workers

\begin{abstract}
Abstrak
Sinetron religi merupakan sinetron yang menampilkan cerita dan segala hal yang berhubungan dengan Islam di dalam ceritanya. Penggambaran yang ditampilkan dalam sinetron religi dapat menimbulkan interpretasi pemirsa yang berbeda-beda. Teks yang ditampilkan memiliki makna. Makna dari teks bukanlah sesuatu yang tetap, melainkan lebih pada bagaimana teks itu mendapatkan makna setelah diterima dan dikonsumsi. Penelitian ini bertujuan untuk menggambarkan bagaimana posisi penerimaan pemirsa terhadap makna spiritual dalam program sinetron religi di televisi. Program yang terutama adalah Layar Kemilau di MNC TV dan sinema Pintu Taubat Indosiar. Penelitian ini menggunakan metode deskriptif kualitatif dan wawancara mendalam dengan tiga informan sebagai teknik pengumpulan data. Analisis penerimaan Stuart Hall digunakan untuk mengidentifikasi dua dari tiga jenis penerimaan; dominan dan bernegosiasi. Penelitian ini mengidentifikasi dominan pemirsa dan bernegosiasi pemirsa sebagai simpulan. Latar belakang informan, pengaruh peer group, kebutuhan akan kesenangan dan gender pemirsa mempengaruhi keputusan untuk menyaksikan program sinetron religi di televisi. Hasil penelitian ini menunjukkan bahwa interpretasi yang didapat pemirsa dapat sejalan atau bertentangan dengan apa yang disajikan sinetron religi.
\end{abstract}

Kata kunci: sinetron religi, reception analysis, pemirsa dominan, pemirsa bernegosiasi, pekerja rumah tangga

\section{Pendahuluan}

Televisi masih menjadi media teknologi yang menarik perhatian manusia masa kini sekalipun perkembangan teknologi komunikasi telah memunculkan media baru, yakni media internet. Menurut Nielsen, penetrasi televisi di Indonesia 94 persen dan dikutip banyak pihak. Televisi swasta di Indonesia baru menjangkau 81 persen penduduk dan penduduk yang mempunyai akses 61 persen. Itu berarti sekitar 130 juta penduduk (Siregar 2013). Sebagai media yang paling akrab, televisi telah menjadi bagian integral dari keluarga sebagian besar masyarakat di Indonesia. Aneka program yang disajikan lewat televisi tidak lain adalah rupa-rupa cara dengannya ia menghadirkan diri ditengahtengah pemirsa. Pemirsa diberi kesempatan menghidupi aneka perasaan dan emosi: sedih, gembira, 
marah, puas dan sebagainya (Batmomolin \& Hermawan 2003:83-88). Menurut Nielsen, program hiburan paling diminati. Sebagai contoh, inilah delapan besar program yang paling diminati: 1 . Tukang Bubur Naik Haji (RCTI), 2. X-Factor (RCTI), 3.Berkah (RCTI), 4. On the spot (Trans 7), 5.Raden Kian Santang (MNC TV), 6. SCTV Music Award, 7. Opera van Java (Trans 7), 8. Cinta 7 Susun (RCTI), (Nielsen 28/4/2013 hingga 4/5/2013 dalam Siregar 2013). Hasil ini menunjukkan bahwa sinetron religi berhasil menempati posisi teratas, bahkan manakala penayangannya bukan di bulan Ramadhan. Siaran-siaran televisi dengan pelbagai program acaranya hadir untuk memenuhi kebutuhan spiritual tubuh yang kecapaian bekerja sepanjang hari dan atau menemani orang-orang yang masih menunaikan pekerjaan rumah tangganya, seperti halnya yang dialami oleh pekerja rumah tangga. Di sela-sela menyelesaikan beban pekerjaan rumah tangga, seperti menyapu, membersihkan lantai, mencuci baju, ataupun memasak, tidak jarang tugas ini dilakukannya sambil menonton televisi. Dari pengamatan awal pada beberapa pekerja rumah tangga, ditemukan bahwa televisi tampak selalu menyala selama mereka berada di dalam rumah sembari mengerjakan tugas rumah tangga. Sinetron menjadi program pilihan bagi pekerja rumah tangga yang umumnya perempuan ini terutama sinetron religi.

Sinetron merupakan satu bentuk aktualitas komunikasi dan interaksi manusia yang diolah berdasarkan alur cerita untuk mengangkat kehidupan sehari-hari, yakni berbagai problem sosial seperti percintaan, perkawinan, kekerasan, dan konflik. Semuanya dipadukan dalam satu kemasan yang menarik untuk ditonton. Perpaduan dari pelbagai hal dalam keseharian itu diramu, sehingga dapat memungkinkan keterlibatan pemirsa dari tingkat emosional sampai praktis. Sinetron dan program-program sejenisnya banyak digemari karena memungkinkan pemirsa mengorganisasi kehidupan sosialnya secara mental, memperkuat kesadaran akan norma sosial yang ada di masyarakat dan kesadaran sense of belonging pada grup sosialnya. Program-program ini merupakan resonansi dari keseharian pemirsa (Batmomolin \& Hermawan 2003).

Sebagai acara yang sedang populer pada stasiun televisi, sinetron religi diharapkan mampu memberikan pengaruh positif dalam mencontohkan kehidupan yang baik dan benar sesuai dengan moral dan ajaran agama. Cerita-cerita yang bernuansakan keagamaan menjadi alternatif penting untuk mengajak pemirsanya mengingat kepada sang pencipta yakni Tuhan Yang Maha Esa, serta contohcontoh perilaku menghormati orang lain, kehidupan berdamai dan saling tolong menolong antar sesama manusia dalam menjalani kehidupan secara baik dan positif. Akan tetapi, para sutradara dan penulis skenario masih mengesampingkan hal penting tersebut. Sinetron religi hanya diproduksi untuk meraup keuntungan besar dan berusaha menarik perhatian masyarakat. Cerita-cerita religi yang ditampilkan pun sedang berkembang dengan unsur mistik dan bernuansa gaib, yang kemudian diklaim sebagai tayangan kegemaran para pemirsanya. Penayangan program-program hiburan di televisi mempunyai daya pikat tersendiri bagi pekerja rumah tangga yang betah duduk di depan televisi dan menikmati program yang ditayangkan. Sebagai media informasi dan hiburan, sinetron religi mampu mempengaruhi siapa pun karena pada dasarnya dalam jiwa manusia yang kurang kritis ada kecenderungan untuk menerima semua sajian dalam media tanpa ragu.

Penelitian ini bertujuan untuk mengetahui bagaimana pekerja rumah tangga memaknai spiritualitas dalam program sinetron religi di televisi. Genre sinetron religi, sinetron yang sarat dengan klaimklaim moral agamis ini mengangkat tema penceritaan berdasarkan hikmah-hikmah yang dikaitkan dengan norma-norma agama, akidah dan syariah. Karakteristik tokoh dalam sinetron ini diberi namanama Islami pun beratribut Islam. Asumsi bahwa pekerja rumah tangga sebagai pemirsa aktif yang tidak begitu saja menerima pesan teks media, melakukan pembacaan dalam praktik menonton yang dilakukannya. Makna teks media yang dipahami juga bersifat polisemi. Menarik kemudian mengamati dan menemukan bagaimana pekerja rumah tangga yang menghabiskan sebagian besar waktunya di dalam rumah, berinteraksi dengan media televisi. Berbagai keberbedaan pola menonton menentukan dinamika penerimaan (resepsi) pemirsa dalam memaknai teks media televisi. 


\section{Metode Penelitian}

Penelitian ini menggunakan metode kualitatif dengan pendekatan analisis resepsi, yaitu penelitian yang mendasarkan pada kesadaran atau cara subyek dalam memahami obyek dan peristiwa dengan pengalaman individu. Analisis resepsi dapat melihat mengapa pemirsa memaknai sesuatu secara berbeda, faktor-faktor psikologis dan sosial apa yang mempengaruhi perbedaan tersebut, dan konsekuensi sosial apakah yang muncul. Analisis resepsi lebih menekankan konsumsi media pada aspek penerimaan tekstual terhadap suatu program tertentu oleh pemirsa. Menurut Dennis McQuail (2005), Reception Analysis adalah suatu studi yang berfokus pada makna, produksi dan pengalaman pemirsa dalam interaksi mereka dengan teks media. Fokusnya pada proses decoding, interpretasi, dan pembacaan, sebagai konsep inti dari Reception Analysis.

\section{Gambar 1. \\ Model encoding/decoding}

\section{Programme a \\ "meaningful" discourse \\ Encoding}

$\begin{aligned} & \text { Meaning } \\ & \text { structures } 1\end{aligned}$
Frameworks
of knowledge
-------------
Relations
of production
------------
Technical
Infrastructure
(production of text)

Decoding

\author{
Meaning \\ structures 2 \\ Frameworks \\ of knowledge \\ Relations \\ of production \\ Technical \\ infrastructure \\ (reception of text)
}

(Sumber: Hall 1980)

Model ini digunakan dalam menjawab permasalahan penelitian ini karena mengakomodasi bagian yang lebih luas dari sekedar struktur, perilaku, dan kinerja pasar. Ia merupakan salah satu bentuk kritis terhadap penelitian komunikasi massa yang mengkonseptualisasikan proses komunikasi dalam bentuk sirkuit sirkulasi atau panah berupa hubungan linear antara pengirim, pesan, penerima, model ini intinya ingin menemukan atribusi dan konstruksi arti (yang dibentuk oleh media) dengan receiver. Salah satu ahli yang membahas analisis resepsi adalah Stuart Hall. Hall mengklasifikasikan bagaimana pemirsa memaknai pesan berdasarkan pengalamannya menjadi tiga jenis, preferred atau dominant, negotiated dan oppositional. Ketiga pengklasifikasian yang diungkapkan Stuart Hall terjadi pada pemirsa yang aktif, yang dengan baik dapat menangkap pesan yang ia terima dan kemudian memaknainya pula. Dalam bukunya A First Look at Communication Theory, EM. Griffin (2003) mengutip penjabaran Hall mengenai ketiga jenis pemaknaan ini, yaitu: 1) Dominant, memaknai berdasar kode yang dominan. Media memproduksi pesan dan pemirsa mengkonsumsinya. Pemirsa mengkonsumsi pesan tersebut berdasarkan makna yang ditawarkan media. Dominant adalah tipe pemirsa yang memaknai teks sesuai dengan budaya yang dominan. 2) Negotiated, memaknai teks berdasarkan nilai budaya yang dominan tapi menolak penerapannya dalam kasus yang spesifik. 3) Oppositional, pemirsa memaknai pesan secara kritis dan menemukan adanya bias dalam penyampaian pesan dan berusaha untuk tidak menerimanya secara mentah-mentah. Dalam hal ini pemirsa berusaha untuk melakukan demitologisasi terhadap teks. 
Secara sederhana, pemikiran Hall juga dapat diartikan bahwa pemirsa berada dalam posisi dominant ketika ia secara utuh berbagi dan menerima serta mengolah kembali pesan-pesan yang ia baca, pada posisi dominant, pesan yang dimaknai pemirsa sesuai dengan hegemonic culture, maka pemirsa secara utuh mengonstruksi pesan dari kelompok dominan. Namun, jika pemirsa mulai memiliki penolakan di antara penerimaannya atas pesan yang ia dapat dari media maka ia menjadi negotiated, di mana pada satu sisi ia membenarkan hegemonic cultureI, tetapi juga mengembangkan pemikirannya sendiri. Tidak selalu pemirsa akan patuh terhadap hegemonic culture, pemirsa bisa saja menolak karena perbedaan pandangan maupun budaya yang ia miliki dengan pesan di media, maka ia menjadi oppositional (Hall in Durham Meenakshi dan Douglas M. Kellner (ed) 2006:172).

Dalam paradigma pemirsa aktif, pemirsa dikonsepsikan memiliki kemampuan melakukan pemaknaan, sebagai produsen makna yang bersifat aktif dan berpengetahuan luas, bukan produk dari teks yang distrukturkan, tetapi makna terikat oleh cara teks distrukturkan oleh konteks domestik dan konteks budaya dalam menonton. Pemirsa perlu dipahami bahwa menonton televisi berkaitan dengan konstruksi makna dan rutinitas kehidupan sehari-hari.

\section{Hasil Penelitian dan Pembahasan}

Tayangan sinetron religi merupakan tayangan yang menceritakan mengenai hal-hal yang berkaitan dengan religius (agama Islam). Pada setiap penayangan terdapat ceramah dari ahli agama atau ustadz/ustadzah. Tayangan sinetron religi dapat dibagi menjadi tiga kategori, yaitu sinetron religi komedi, sinetron religi rumah tangga, dan sinetron religi misteri. Sinetron religi komedi merupakan jenis sinetron yang berisi drama kelucuan-lucuan yang mengajak pemirsa tertawa namun juga berisi hal-hal yang berkaitan dengan religi (agama Islam). Sinetron religi rumah tangga merupakan jenis sinetron drama yang berkaitan dengan hal-hal yang religi (agama Islam) yang mengangkat masalahmasalah dalam rumah tangga, sedangkan sinetron religi misteri merupakan jenis sinetron drama yang berkaitan dengan hal-hal yang religi (agama Islam) namun dengan mengangkat masalah misteri atau menciptakan situasi yang mencekam. Sinetron religi rumah tangga menjadi sinetron religi yang paling banyak dan sering ditayangkan di televisi. Informan penelitian ini juga memilih sinetron religi rumah tangga sebagai pilihan sinetron yang paling digemari.

Secara garis besar, tayangan sinetron religi membahas religiusitas. Ini adalah suatu keadaan di mana terdapat keterikatan individu yang besar terhadap agamanya, bagaimana menjalankan ajaran agamanya dalam kehidupan sehari-hari. Tayangan religi hakekatnya mengandung hal-hal yang berhubungan dengan keagamaan ini yang memperlihatkan hubungan manusia dengan Tuhan Yang Maha Esa harus mampu menyampaikan sisi positif yang sangat dominan dalam cerita sehingga tidak melenceng dari ajaran agama dan tidak mendapat respon negatif dari masyarakat apabila menampilkan sisi negatif yang berlebihan. Pesan moral kebaikan yang disampaikan dalam setiap tayangan religi khususnya diharapkan mampu menjadi alternatif pembelajaran moral secara tidak langsung dengan menampilkan perilaku-perilaku bermoral.

Muhammadun AS (2004) dalam artikel yang berjudul Ramadhan dan Fenomena Selebritisme Agama berargumen bahwa fenomena maraknya suguhan nilai ritual religious di televisi selama bulan Ramadhan disebabkan oleh dua hal. Pertama, pemahaman yang dangkal atas ibadah puasa. Masyarakat terjebak dalam pragmatisme fiqh oriented. Puasa diartikan sebatas pada tidak makan dan tidak minum, sehingga nilai-nilai toleran, simpati, terbuka dan ramah yang menjadi dasar makna puasa menjadi kabur bahkan terdistorsi. Agama ditampilkan begitu massif tanpa melihat realitas sosial yang melingkupinya. Kedua, berangkat dari pemikiran Kuntowijoyo tentang budaya masjid dan budaya pasar, saat ini budaya pasar (yang selalu mementingkan materi) telah mengalahkan budaya masjid (yang jauh dari kesan hedonisme karena budaya masjid menggambarkan budaya masyarakat yang bersih dan jujur). Berbagai tayangan televisi ritual-religius selama Ramadhan yang dikemas dalam beragam program acara terjebak dalam pemahaman Islam yang simbolis-verbalis (dalam Surya 2008). Senada dengan apa yang diungkapkan di atas, sinetron religi yang teramati yakni, Layar 
Kemilau MNC TV dan Sinema Pintu Taubat Indosiar sebagai pilihan informan, menunjukkan bahwa makna spiritual ditampilkan dalam kaitannya dengan simbol-simbol keagamaan dan praktik-praktik agama peribadatan. Spiritualitas televisi masih pada batas image dan performance bernuansa Islami.

Berhubungan dengan simbol, simbol-simbol Islam dijadikan sebagai sebuah komoditas penarik massa, akan tetapi juga bisa menjadi faktor yang riskan karena Islam memang merupakan agama mayoritas di Indonesia. Di dunia teologi "simbol" adalah sebuah sinonim dari "kepercayaan" (Sobur 2006). Simbol agama menurut Geertz,

"These symbols" establish powerful, pervasive, and long-lasting moods and motivations,"we can abbreviate this by saying that religion makes people feel things and also want to do things. Motivations have goals, and they are guided by an enduring set of values-what matters to people, what they think is good and right (Pals 1996)".

Dari pernyataan tersebut bisa ditangkap bahwa simbol yang berhubungan dengan agama dan keyakinan bisa menyebabkan seseorang merasakan atau melakukan sesuatu. Memotivasi serta mempunyai tujuan-tujuan tertentu dan orang yang termotivasi tersebut akan dibimbing oleh seperangkat nilai tentang apa yang penting, apa yang baik dan buruk, apa yang benar dan salah. Simbol-simbol Islam yang direpresentasikan dalam sinetron religi dalam Layar Kemilau MNC TV dan Sinema Pintu Taubat Indosiar menimbulkan adanya kedekatan emosional, sehingga simbolsimbol Islam tersebut mengalihkan pemirsa pada maksud pesan utama dan lebih memaknai representasi yang diciptakan. Layar Kemilau MNC TV dan Sinema Pintu Taubat Indosiar menyajikan spiritualitas dalam konteks budaya massa. Penggunaan simbol-simbol bernuansa Islami dan ritual keagamaan menunjukkan makna spiritual yang menjadi preferred reading.

\section{Posisi penerimaan pekerja rumah tangga terhadap makna spiritual}

Penelitian ini merupakan hasil analisis resepsi dari in-depth interview dengan tiga informan. Para informan merupakan pemirsa tayangan sinetron religi Layar Kemilau MNC TV dan Sinema Pintu Taubat Indosiar berasal dari tingkat pendidikan dan jenis kelamin yang sama. In-depth interview dilakukan secara informal dengan mengajukan pertanyaan-pertanyaan yang bersifat terbuka. Dari penelitian yang sudah dilakukan, peneliti menemukan bahwa Informan I, II, dan III menerima makna dominan yang ditawarkan oleh tayangan religi pada Layar Kemilau MNC TV dan Sinema Pintu Taubat Indosiar.

Dalam kategorisasi encoding/decoding Stuart Hall, informan masuk dalam kategori DominantHegemonic Position yaitu, audiens TV mengambil makna yang mengandung arti dari program TV dan meng-decode-nya sesuai dengan makna yang dimaksud (preferred reading) yang ditawarkan teks media. Audiens sudah punya pemahaman yang sama, tidak akan ada pengulangan pesan, pandangan komunikator dan komunikan sama, langsung menerima. Program sinetron religi pada Layar Kemilau MNC TV dan Sinema Pintu Taubat Indosiar diresepsi oleh ketiga informan sebagai sebuah sinetron yang memiliki tujuan untuk menyampaikan ajaran agama dengan cara mengangkat nilai-nilai agama dan mendasarkan isi tayangannya pada kitab suci suatu agama tertentu, dalam hal ini adalah agama Islam. Meskipun sebagian dari informan juga memiliki penerimaan bahwa sinetron religi tidak hanya berdasar pada agama Islam saja tetapi juga pada agama-agama lainnya.

Informan I menjadikan tayangan Layar Kemilau MNC TV sebagai sebuah idola. Bahkan dia tidak segan menonton tayangan religi ini secara berulang-ulang. Dia menyebutkan bahwa episode-episode yang ditayangkan pada siang hari, terkadang ditayangkan kembali pada program acara sejenis pada waktu penayangan lain seperti pagi atau malam hari. Dari pemaknaan yang dilakukannya, dia menilai bahwa tayangan religi Layar Kemilau MNC TV dirasa sudah sesuai dengan oleh apa yang diyakininya, yaitu syarat dengan muatan informatif dan hiburan. Pengamatan yang telah dilihat Informan I sejauh ini menunjukkan apa yang ditampilkan oleh tayangan religi Layar Kemilau MNC TV sesuai dengan kenyataan yang ada. Informan I selalu mengkaitkan bahwa acara Layar Kemilau MNC TV menampilkan fakta tentang sesuatu yang terjadi saat ini di masyarakat dan lingkungan di sekitarnya. Dia menerima fakta-fakta yang ditampilkan oleh Layar Kemilau MNC TV. Informan 
secara kuat terpengaruh dengan apa yang disajikan oleh Layar Kemilau MNC TV dikarenakan pengetahuannya terhadap realitas media sangat kurang. Simbol-simbol keagamaan yang direpresentasikan pada tayangan religi semakin meneguhkan spiritualitas yang diyakininya seperti ibadah sholat lima waktu, sikap ketundukan pada Allah dan sikap kepasrahan atas apa yang dialami sebagai manusia. Informan I memiliki resepsi bahwa citra Islam yang diangkat pada kedua sinetron religi menampilkan realitas kehidupan sehari-hari, sebagaimana persoalan yang dialami dalam rumah tangga, sekalipun informan juga mengakui ada juga permasalahan yang dianggap terlalu berlebihan.

Berikutnya adalah posisi negosiasi ketika teks media diterima sebagai sebuah pesan yang kurang tepat, lantas dibuat negosiasi atau alternatif pandangan terhadap hal tersebut. Teks Layar Kemilau MNC TV dan Sinema Pintu Taubat Siang atas makna spiritual diterima sebagian dan sebagian lagi dinegosiasikan dengan kerangka pikir mereka masing-masing. Beberapa informan menganggap bahwa pengalaman-pengalaman religi yang ada dalam tayangan religi Layar Kemilau MNC TV dan Sinema Pintu Taubat Siang menunjukkan bahwa pengamalan agama Islam seseorang bergantung pada pemahamannya terhadap Islam dan menjalankan ibadahnya.

Tipe oposisi yang mana pemirsa menolak mentah-mentah apa yang ditawarkan makna yang dipreferensikan Layar Kemilau MNC TV dan Sinema Pintu Taubat Indosiar, informan I,II dan III jarang melakukannya. Bagi mereka, apa yang tidak ada yang tidak masuk akal dari apa yang ditayangkan sinetron religi tersebut. Konflik rumah tangga yang menjadi basis utama dalam setiap episode dalam Layar Kemilau MNC TV dan Sinema Pintu Taubat Indosiar dirasakan sebagai bagian refleksi atas apa yang dialami oleh kebanyakan orang pada dunia nyata. Makna dan pesan yang diberikan oleh produsen media kepada audiensnya belum tentu dimaknai sama, tergantung pada wacana dan pengalaman subjektif masing-masing. Bisa jadi makna dan pesan tersebut dimaknai sama, dinegosiasikan berdasarkan nilai-nilai dominan yang ada atau dimaknai berbeda. Dari hasil penelitian yang dilakukan terhadap beberapa informan diketahui bahwa terdapat perbedaan pemaknaan yang dilakukan masing-masing informan terhadap teks tayangan religi yang bersifat terbuka. Pemirsa adalah pemirsa aktif yang melakukan proses pemaknaan dan proses ini berbeda satu sama lain tergantung pada pengetahuan, pengalaman dan kebudayaan yang melingkupi dunia informan.

Secara umum para informan mengatakan bahwa sinetron religi adalah tayangan religi yang mengandung pesan atau nilai agama dan tidak terpaku pada penggunaan simbol-simbol keagamaan. Para informan dalam pengalamannya berinteraksi dengan teks mampu mengidentifikasi muatan cerita dan tema-tema yang sepertinya tidak realistis menggunakan pengalaman dan pengetahuan yang mereka miliki. Dalam proses konsumsi dan proses produksi makna yang dilakukan oleh para narasumber, ternyata tingkat pendidikan dan jenis kelamin yang sama memiliki tipe penerimaan yang berbeda terhadap teks tayangan religi di televisi yang diamati.

\section{Simpulan}

Televisi merupakan sarana untuk menyampaikan konstruksi sosial kepada masyarakat. Sinetronsinetron yang ditayangkan sarat dengan makna yang dibuat atau konstruksi oleh produser. Penggambaran yang diberikan sinetron terkadang berlebihan dan belum tentu sesuai dengan kenyataan yang ada di masyarakat, akan tetapi apa yang ditampilkan di televisi dinilai masyarakat sebagai sesuatu yang ideal. Mereka menjadikan hal itu sebagai tolak ukur untuk menilai sesuatu ideal atau tidak. Konstruksi makna spiritual yang ditampilkan sinetron religi di televisi masih terbatas pada penghayatan agama yang telah terkomodifikasi. Interpretasi pemirsa dipengaruhi oleh berbagai faktor sosio-kultural, seperti jenis kelamin, latar belakang pendidikan, latar belakang budaya, lingkungan (keluarga, pergaulan, dan tempat tinggal), pengalaman dan pengetahuan. Interpretasi yang didapat pemirsa dapat sejalan atau bertentangan dengan apa yang disajikan sinetron religi. Melalui faktorfaktor ini dapat ditelusuri alasan mengapa pemirsa tidak setuju dengan konstruksi makna spiritual di televisi. Misalnya, kegiatan keagamaan atau pengajian-pengajian yang diikuti di luar rumah yang dilakukan pekerja rumah tangga di lingkungan tempat tinggalnya semakin memberikan tingkat 
pengetahuan mengenai nilai-nilai agama. Seperti informan I terlihat lebih kritis dalam memberikan tanggapan terhadap muatan cerita negatif dalam sinetron religi dan tema cerita yang tidak realistis.

\section{Daftar Pustaka}

Batmomolin L dan Hermawan F (2003) Budaya Media: Bagaimana Pesona Media Elektronik Memperdaya Anda. Flores: Penerbit Nusa Indah hal 83-91.

Griffin EM (2003) A First Look at Communication Theory. Boston: McGraw-Hill. Hal. 374-375.

Hall S (2006) Encoding-decoding. Dalam Meenakshi G. Durham dan Douglas M. Kellner (Eds). Media and Culture Studies: Keyworks. Oxford: Blackwell Publishing. Hal. 172.

http://hiburan.kompasiana.com/televisi/2013/07/23/head-to-head-dan-rating-sinetron-religi-

578436.html. Diakses pada tanggal 29 Oktober 2013.

McQuail D (2005) Mass Communication Theory. London: Sage Publications hal. 56.

Muhammadun AS (2004) Ramadhan dan Fenomena Selebritisme Agama. Diakses pada tanggal 29

Oktober 2013. http://www.kompas.co.id/kompas- cetak/0410/15/opini/1325109.htm.

Ombrill (2013) Head to head dan rating sinetron religi. Diakses pada tanggal 29 Oktober 2013.

Pals DL (1996) Seven Theory of Religion. New York: Oxford University Press hal 244.

Siregar AE (2013). Isi Televisi dan Diktator "Rating". SKH KOMPAS pp.6.

Sobur A (2006) Analisis Teks Media Suatu Pengantar untuk Analisis Wacana, Analisis Semiotik, Analisis Framing. Bandung: PT Remaja Rosdakarya hal 42-43.

Surya YWI (2008) Citra perempuan Islam kontemporer: Representasi perempuan Islam dalam sinetron Ramadhan. Jurnal Penelitian Dinas Sosial 7 (2):77-87. 